THE IARGEST REFLECTING TELEBCOPE IN THE WORLD to the iron fork just mentioned, is a hollow cube with BY GRACE AGNES THOMPSON.

The astronomical observatory connected with Harvard University has just completed the mounting on its grounds at Cambridge, Mass., of a 5 -foot reflecting telescope, purchased from the estate of Dr. A. A. Common at Ealing, England, which is at present the largest astronomical instrument in the world.

The biggest telescope in the world is an expression that has changed its meaning a number of times. A few years ago it was an instrument which we would call very small to-day-only a few inches in diameter. Gradually the size of each new instrument was increased, until people spoke of the 40-inch Yerkes telescope as the largest telescope in active use in the world, and indeed it is still the largest refracting telescope in the world. For until certain difficulties in the making of large disks of optical glass have been overcome, it is probable that no larger lens will be successful, and reflecting telescopes must do all the work required of a very large instrument. The Common telescope is 20 inches wider than the diameter of the Yerkes.

The largest telescope ever constructed was a 6-foot instrument made by Lord Rosse in 1842 , and set up in the park of his castle in Ireland. But for various reasons this telescope was not long of any use, and it was abandoned many years ago. It is an interesting relic, still to be seen with its mirror of metal and its clumsy mounting at Parsontown, Ireland. The Common telescope has an excellent mirror of optical glass, and is mounted in a wonderfully ingenious and practical way. Only the principal portions of the original instrument have been used by the Harvard Observatory, and an entirely new system of control has been worked out, by which electricity has been called into a field heretofore untried.) [Even the mounting of this telescope is as remarkable as it is unusual. In stead of being supported by a pedestal or foundation pier of cast iron, cement, or masonry firmly built upon the ground, like all other large equatorial telescopes, it is held in position by a hollow cylinder that floats in a tank of water. For this, a deep excavation was made on the spot where the telescope was to stand-the first sod being turned September 28, 1904and a tank was constructed with thick walls of solid concrete, 15 feet deep at the farther end and 21 feet long, the bottom sloping upward from the deep end at an angle of about $45 \mathrm{deg}$. to the surface of the ground. In this tank the water-tight steel float or cylinder, which is 18 feet long and ? feet 8 inches in diameter, is ballasted at the same angle as the bottom of the tank, this angle being that of the celestial pole as being that of the celestial pole as
measured at Cambridge, and the measured at Cambridge, and the cylinder acting as the polar axis of the telescope. The buoyancy of the water supports its weight, and delicate pivots at each end serve to steady it in position and allow it to turn readily. Above this, and securely attached to it by a strong fork and bolts, is the tube of the telescope, which is seen in position in the accompanying photograph. The tube is not circular as in most other telescopes, but rectangular. Nor has it solid walls. The upper part of the tube, for a distance of 15 feet, is a skeleton framework of angle iron, with an inside measurement of 6 feet, which is now covered with heavy canvas. The lower end, which contains the mirror and is bolted

to the iron fork just mentioned, is a hollow cube with sides 6 feet in length that are made of steel plates.
The whole structure weighs over 20 tons, but is so
delicately poised that it appears to have no weight at all, and it can be moved in any direction, up, down,

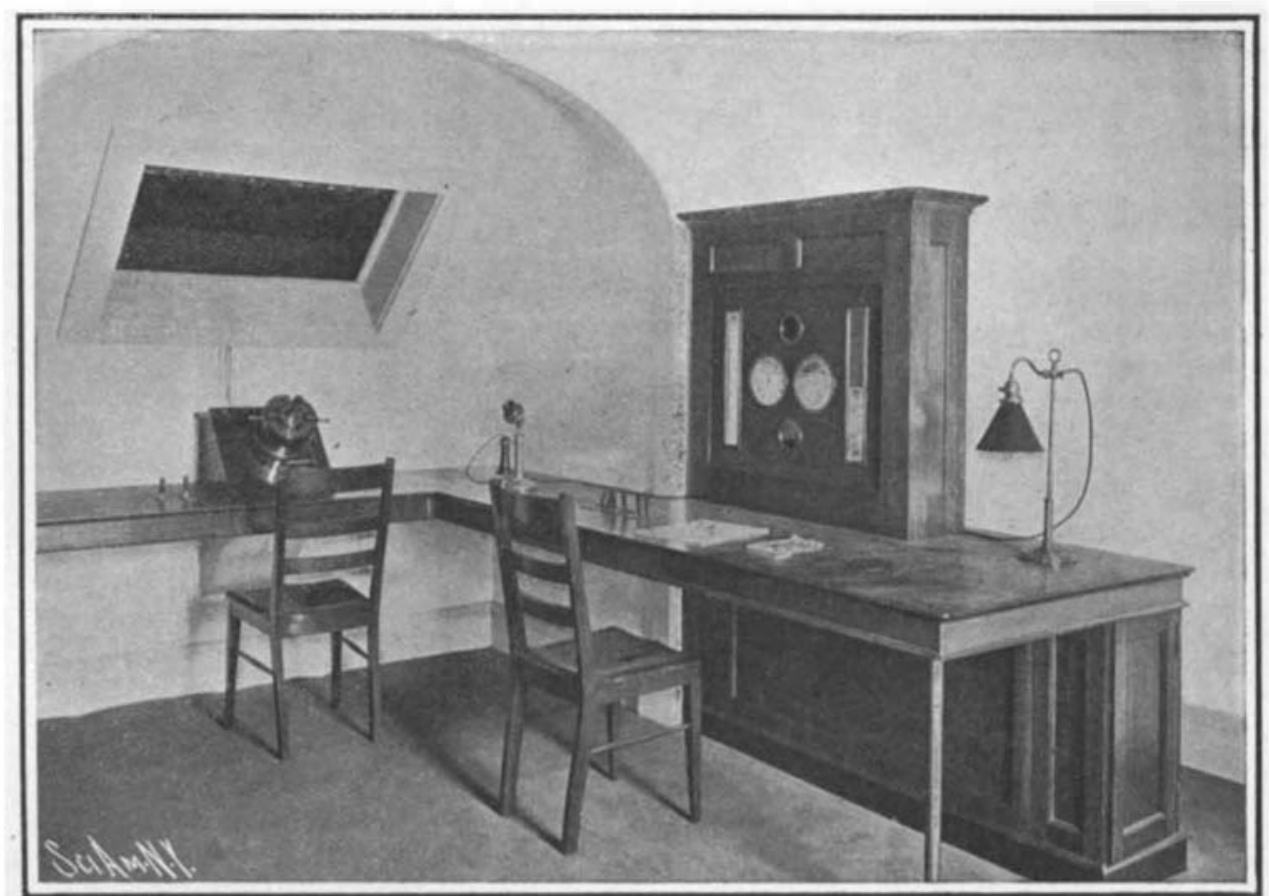

The Observing Room of the Common Telescope. The Eyepiece of the Telescope is Under the Window.

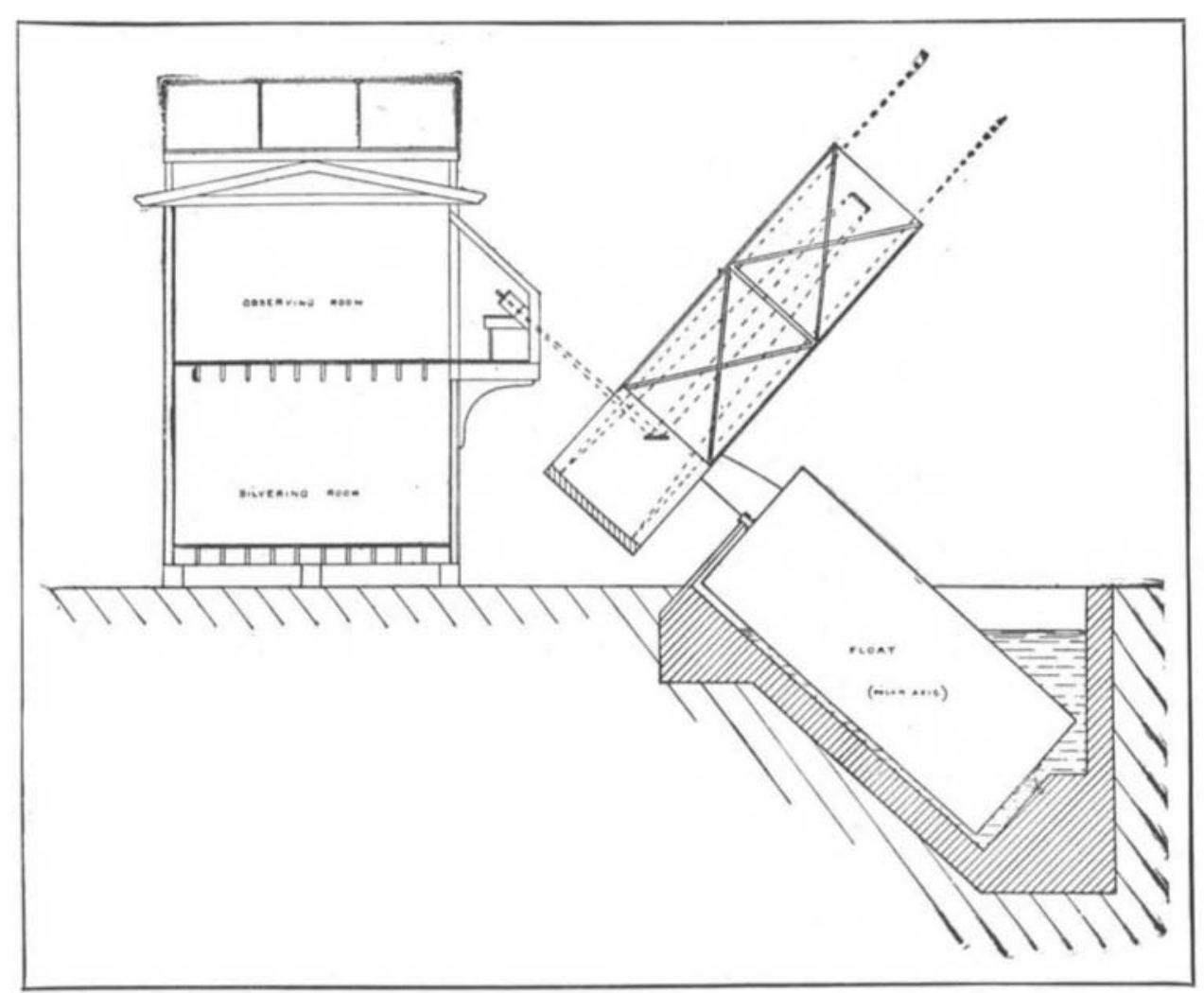

Diagram of the Common Telescope, Showing Manner of Mounting.

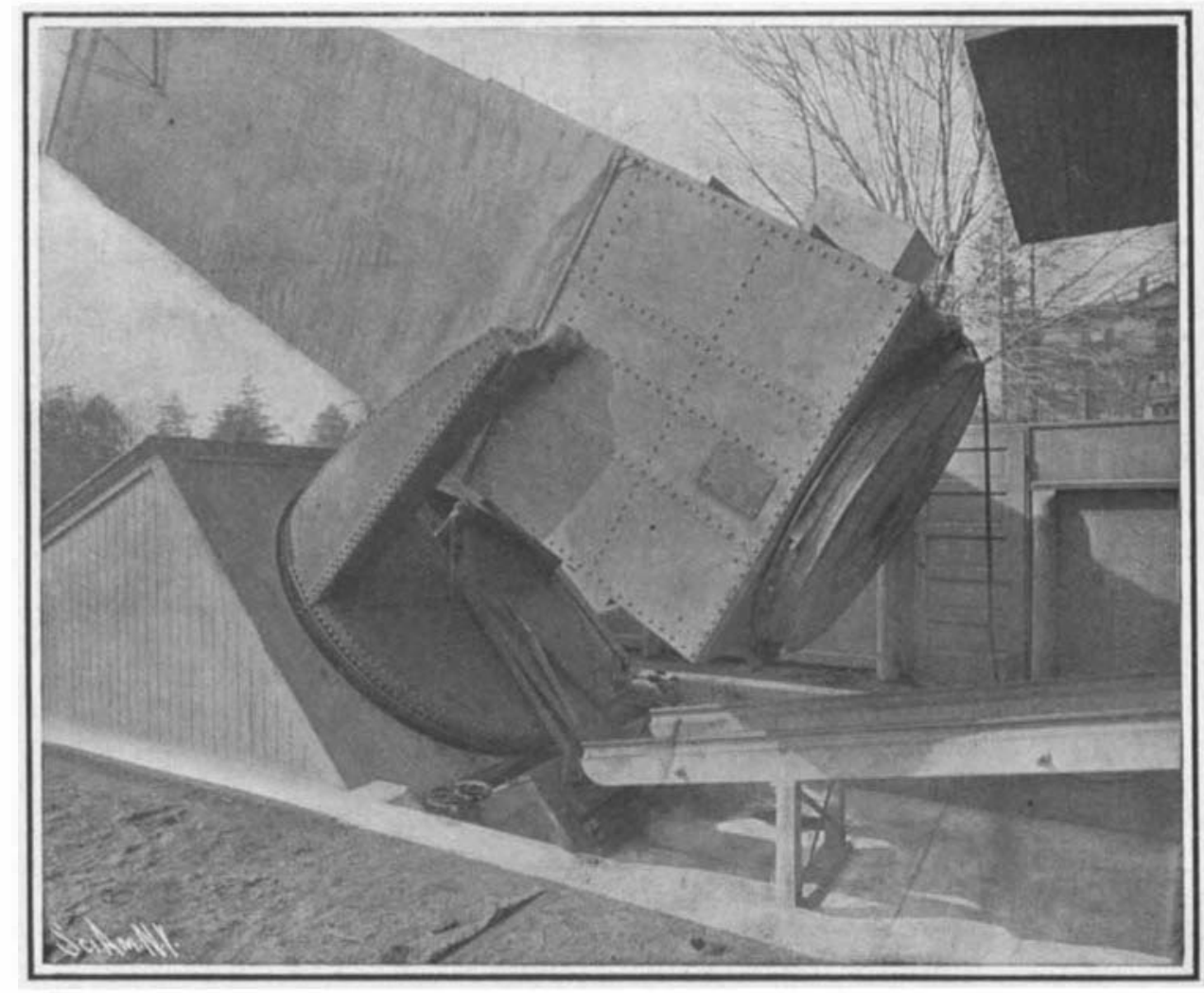

The Lower Part of the Common Telescope and Its Support on the Float. The Image is Refiected to an Eyepiece in the Building at the Right. or sidewise, without the slightest jar or slip. The telescopes in most observatories are handled by elabrate mechanical devices including clockwork that runs by a system of weights, but the Common teleand controlled entirely by electricity. However elaborate and ingenious, hand machinery must always be crude and inconvenient. Electricity insures a nicety and regularity in moving and guiding an instrument that can be fully depended upon, and at the same time it simplifies the mechanism. The Har vard Observatory has been the pioneer in demonstrating this fact. For several years all the clockwork required for following for the various instruments here has been driven by electric motors. The necessary mechanism for this is the result of much thought, invention, and experiment on the part of Mr. Willard P. Gerrish, of the observatory, under whose direction the Common telescope has been in stalled. Electric power is applied not only to the clockwork, but to the mechanism for handling the Common telescope. At no other observatory is electricity so employed. The eyepiece of the Common telescope, to which the image of the star is carried by a system of mirrors, is situated at a desk in the "observing room" in the second story of the small building shown in the photograph. Small switches located at the same desk control motors and clutches, by means of which the telescope may be swung at different speeds. A small motor synchronized by an accurate clock gives a uniform motion for following, while dials and indicators at the recorder's desk show at a glance the exact position of the telescope and the motion that is being imparted to it. Other dials register automatically the - measures made by photometric ap. paratus used by the observer at the eyepiece. Thus observer and recorder may work together comfortably in a warm room, whatever the conditions in the open air.

On the first floor, under the observing room, is the silvering room, where the great mirror, which is a disk of glass 5 inches thick and 60 inches in diameter, weighing with its cell nearly two tons, may be rolled in over a kind of railroad on to the silvering table, when it requires a recoating of silver.

One other fact connected with this telescope is interesting. It has been mounted in the open air. This is a very unusual procedure, but is expected to prove as successful as convenient. It is an experiment made chiefly as a matter of economy, since in dispensing with any dome or shelter over so large an instrument, a very considerable expenditure has been saved with out any injury whatever to the instrument.

The Common telescope is a modified form of the Cassegrainian type; that is, the light rays, after passing down the length of the tube to the great mirror, are reflected back to a second, convex in form, placed in the axis of the tube within the focal lengths of the rays, from this again toward the large mirror to a third placed diagonally, by which the image of the star is sent into the eyepiece. As has been stated, it is also an equatorial; in other words, a telescope mounted so that its motion is on an axis parallel to the earth's axis, an inclination which corre sponds to the latitude of the observatory, while the telescope proper is attached to this polar axi by means of a second axis, called the declination axis. Since both the telescope and the polar axis rotate freely, by this double motion, when the image of a star has 
once appeared in the field of the telescope, a rotation of the polar axis east to west in sidereal time make the telescope follow the apparent motion of the star, so that it remains constantly in the field until it has passed below the horizon. The Common telescope is, therefore, not only, well adapted to photographic pur poses, as intended by Dr. Common, but to the photometric work to which it has been assigned at Harvard Observatory.

This photometric work, or measuring the light of the stars, has been an important part of the routine in Cambridge for more than a quarter of a century, and is the chosen life wotk of Prof. Edward C. Pickering, director of the observatory, who devotes to it from two to four hours of each clear night. He has determined the light of over four thousand stars, an made more than one hundred thousand measures of them. But heretofore a 12-inch telescope is the largest instrument that has been available to him for the work, and only stars of the twelfth magnitude and brighter could be measured. The Common telescope, however, from its great aperture, is expected to show stars of the seventeenth or eighteenth magnitude or fainter, thus opening to astronomy a scientific possibility whose value can hardly be estimated.

\section{Disposal of Town Refuse.}

Several short papers on the disposal of refuse in American cities were recently communicated by different authors to the New York section of the Society of Chemical Industry, and the papers have been published in the current issue of the Journal of that Society Hitherto, dumping of the refuse on low-lying meadowland has been the method of disposal most commonly adopted in American towns, although gar bage furnaces have been used there to a certain extent for more than twenty years, and Mr. Rudolph Hering states that there is no city in the United States where all the city refuse is mixed and properly incinerated. Referring to the removal of garbage from hotels and restaurants in New York, Mr. Morse says that the quantity of garbage taken away by private agency amounts to from 15,000 to 20,000 tons per an num, but that the best hotels are now recognizin the advantage of a garbage destructor. At the new Hotel Astor a destructor equipped with a boiler for low-pressure steam is about to be installed. Some interesting information concerning the work of the New York Department of Street Cleaning is contained in the paper communicated by Mr. Edward D. Very. He says that the wastes of New York city are on the average proportioned as follows: Household ash, 47.5 per cent; steam ash, 18 per cent; street sweepings, 18.5 per cent; rubbish, 6 per cent; garbage, 10 per cent The garbage received at the reduction plant in Jamaica Bay contains 71 per cent water, 6 per cent rubbish, 20 per cent tankage, and 3 per cent grease. The grease is extracted by digesting the garbage with steam and then passing the garbage pulp through hydraulic presses to express the presses to express grease and water. The and has a dark brown color. The greater portion is exported, and is used for making soap and candles. Tankage is the solid fib rous matt the presses, and is us a fertiller base or filer. It appears probable that in the 1 a rgest American towns the European practice of incinerating the refuse in destructors erected within the towns will be generally adopted in the immediate future.

The work of partially reconstructing the wooden lattice-work pillars and supporting platform, on which will rest the shear legs, derrick, boiler, winch, etc., for raising the 160 ton Rammerhead crane at

the Keyham Extension, Devonport, is nearing completion, and the mounting of the lifting appliances will coincide with the delivery of the components of the great crane. While the test load was being lifted, the breaking of the supporting pin of the shear leg caused it to collapse and fall to the ground, carrying with it the boiler, winch, and a portion of the platform, and also damaging the pillar nearest the edge of the basin. This accident has necessitated the partial reconstruction referred to, also the retiring and strengthening of the remaining pillars. The complete structure rests on a trolley, with bogie wheels, having a lateral movement parallel to the crane pit.
PANAMA CANAL: FINAL PLAN AND PREBENT CONDITION OF THE WORK.

During the past year it has been our pleasure to record the satisfactory progress which has been made in the development of the final plans, and in the prosecution of the actual work of construction of the Panama Canal. In the present article we give a description of the plans of the canal as revised and finally approved, and statements of the work done by the French company, of the total excavation required for the whole canal, of the amount of work completed since American operations commenced, together with

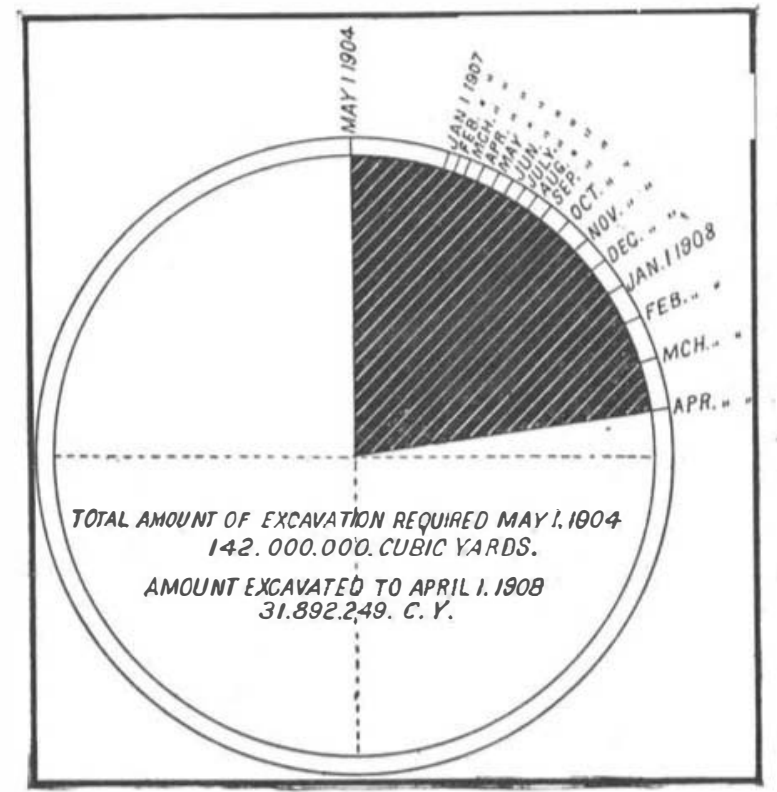

DIAGRAM BHOWING IN BLACR BHADING THE AMOONT OF EXCAVATION COMPLETED BY APRII, 1908, ON THE PANAMA CANAL.

a summary of the appropriations made for the canal and of the mone $y^{\prime \prime}$ so far expended.

TYPE or Canal.-The canal will have a summit elevation of 85 feet above the sea, to be reached by flight of three locks located at Gatun, on the Atlantic side, and by one lock at Pedro Miguel and a flight of two at Miraflores, on the Pacific side; all these locks to be in duplicate, that is, to have two chambers, side by side. Each lock will have a usable length of 1,000 feet and a width of 110 feet. The summit level will be maintained by a large dam at Gatun and a small one at Yedro Miguel, making the great Gatun Lake, which will have an area of 164.23 square miles. A small lake, about two square miles in area, with a surface elevation of 55 feet, will be formed on the Pacific side between Pedro Miguel and Miraflores, the to land on both sides of the canal are to be 500 feet wide, and the cuts in the shallow parts of the lakes from 500 to 1,000 feet wide. The canal will have a minimum depth of 41 feet.

Amount of Work Done by the French.-The amount of material excavated by the old and new Panama Canal companies was $81,548,000$ cubic yards. It was estimated in the report of the Commission for 1901 that $36,689,965$ cubic yards of the prism excavated by the French would be useful in the main line of the new canal, to which must be added the prism excavated by the company since the date of that report, $3,510,231$ cubic yards, making a total of $40,200,196$ cubic yards. This amount will be reduced by the submergence of the channel between Gatun and Bohio, which would have been utilized by the plan of the Commission of 1901, but not in the present project. Total Amount of Excavation.-The following is the
total estimated excavation required, for the whole canal based on the present working plans

In canal prism .......... $106,931,849$

Excavation for locks, regulating works,

diversion channel, and sea level chan nel, from La Boca to Miraflores. ...

Dredging entrance to old canal at Colon for

wharf purposes, and to aid in construc-

tion of Gatun works; and at Panama to

keep channel open to La Boca......

$7,039,607$

Total

$142,334,856$

For purpose of comparison, it may be stated that the estimated amount of excavation required in the canal prism for a sea-level canal, as recommended by the majority of the Board of Consulting Engineers, was $231,026,477$ cubic yards

Steam Shovel Equipment.-Thirty-two 95-ton, twenty-eight 70-ton, three 45-ton, and one 38-ton steam shovel, or a total of sixty-four steam shovels (of which three have been assigned to the Panama Railroad), are now in commission; six 95-ton, fourteen 70-ton, and seven 45-ton steam shovels are either en route or have recently been delivered, and will soon be in use; and in addition, ten 95-ton steam shovels will be delivered in the near future.

Force EMPLOYED.-In the month of February, 1908, there were approximately 44,000 employees on the Isthmus. on the rolls of the Commission and of the Panama Railroad, about 5,500 of whom were Americans. There were actually at work on February 26, 1908, 32,318 men-25,888 men for the Commission, and 6,430 for the Panama Railiroad.

Material Excavated by the United St'.tes.-The two accompanying diagrams show with great clear ness both the amount of work already completed on the canal and the steadily growing rate of in. crease month by month, since actual work was commenced by the United States in May, 1904. It will be seen that in the first month, and, in fact, during the first twelve months, the amount of material taken out was insignificant, ranging from 19,695 cubic yards to a maximum of 132,840 cubic yards a month. In the spring of 1905, however, monthly progress began to show a more' or less steady increase. This was duo to the fact that the preliminary work in the way of reconstructing the Pan. ama Railway, laying new track, and providing suitable dumps, was making headway, and the excavat. ing plant was being placed in position for doing effective work. The largest excavation in any ,ne month in 1905 was 233,974 cubic yards, which was taken out in December of that year. In 1906 the monthly excavation for the first time passed the half AND BHOVELS BINCE AMERICAN OCCUPATION.

valley of the Rio Grande being closed by a small dam and the locks at Miraflores.

Length, Width, and Depth of Canal.-The canal is to be about 50 miles in length from deep water in the Caribbean Sea to deep water in the Pacific Ocean. The distance from deep water to the shore line in Limon Bay is about $4 \frac{1}{2}$ miles, and from the Pacific shore line to deep water is about 5 miles; hence the length of the canal from shore to shore will be approximately $401 / 2$, miles.

The bottom width of the canal will vary from 200 feet in Culebra cut to an indefinite width in the dee waters of the lakes. The approaches from deep wate million mark, the maximum monthly output being 538,254 cubic yards in October of that year. In 190 ? the rate of excavation began to advance by leaps and bounds, rising from 820,099 cubic yards in January to ress was maintained steadily in January, February, reached in March, when the enormous total of 3,480 . 270 cubic.yards was excavated in a single month. The amount of excavation in April was somewhat less amount of material taken out under American operetion up to about $35,000,000$ cubic yards, or about one $2,201,734$ cubic yards in December. This rate of progand March of the present year, the highest figure being than this, but it was sufficient to bring the total 